\title{
EFFECT OF DIRECT REDUCED IRON ON FERROUS OXIDE CAPACITY OF SLAG IN ELECTRIC ARC FURNACE.
}

\author{
Abdelwahed, H. A. ${ }^{*}$; Shaheen, M. ${ }^{\dagger}$; Megahed, G. M. ${ }^{*} ;$ Ahmed, E. ${ }^{\dagger}$ and Meraikib, M. ${ }^{*}$ \\ Al Ezz Flat Steel Company. \\ ${ }^{\dagger}$ Metallurgical Engineering, Faculty of Petroleum and Mining Engineering, Suez University. \\ * Tabbin Institute for Metallurgical Studies.
}

\begin{abstract}
Slag and the corresponding hot metal samples were collected just before tapping from electric arc furnace of Ezz Flat Steel Company (EFS) and analyzed. The temperature of hot metal was measured before tapping.

The analyses of slag and hot metal together with the metal temperature were used to estimate the activity coefficient and activity of total ferrous oxides in slag, also investigate carbon and oxygen activity coefficient in steel according to the statistical theory of regular ionic solutions.
\end{abstract}

The oxides capacity of the slag was also assessed. The variation of carbon and oxygen activity in hot metal with the concentration was also treated.

The ratio of activity to concentration of total ferrous oxides is constant and equal to 0.0179. The activity coefficients of oxygen and carbon in steel are 0.810 and 1.0704, respectively.

The oxides capacity of the slag increases with increasing carbon concentration in the bath and with increasing DRI proportion in the charge.

\section{Keywords}

Electric arc furnace, DRI, slag oxide capacity.

\section{INTRODUCTION}

World scrap availability trends, fluctuation in scrap prices and rising tramp elements levels in steel all have possibly contributed in compelling EAF producers to consider alternatives to scrap. ${ }^{[1]}$

EFS start using direct reduced iron DRI as alternative to scrap in EAF metallic charge. EFS EAF running with DRI in metallic charge faces varying in process conditions such as EAF slag behavior, which affect on all process parameters. The present work investigates the effect of DRI on slag ferrous oxide capacity to control the level of ferrous oxide in the slag.

The state of oxidation of a steel bath is vital importance in controlling the reactions between EAF slag and metal in steelmaking process. It influences both steel yield by metal losses in the slag and the quality of steel being produced. 
The state of bath oxidation, in turn, is determined by the oxidizing capacity (oxidizing power) of the slag which refers to its ability to supply oxygen to the bath in order to oxidize undesired elements dissolved in the metal. ${ }^{[2]}$

There is, however, no clear opinion on selecting a criterion for the oxidizing capacity of slags. Thus, whereas some investigators ${ }^{[3]}$ consider the concentration of $\mathrm{FeO}$ to be the most objective criterion of slag oxidation, others ${ }^{[3]}$ claim that divalent and trivalent iron should be accounted for when monitoring steelmaking processes ${ }^{[4]}$.

Moreover, it has been reported that the oxidizing power of slag is mainly determined by the content of free $\mathrm{FeO}^{[3-4]}$. The total molar concentration of ferrous oxide and ferric oxide is assumed to characterize the oxidizing power of a slag.

It should also be noted that, although the concentration of iron oxide is frequently used to refer to the oxidizing capacity of the slag, the latter, however, is difficult to be defined in terms of bath oxidation because of the influence of carbon on the oxygen dissolved in the metal, which almost erases any relation with the slag composition ${ }^{[5]}$.

Taking into consideration that the main source of oxygen transfer to the bath is the iron oxide in the slag, then the oxidizing capacity is determined by the activity rather than by the concentration of iron oxide. At high iron oxide activity in the slag, oxygen is transferred to the bath and vice versa at very low activity.

The main aim of the present work is to develop an "oxide capacity" which takes into account the oxygen equivalence and not the activity of total iron oxide in the slag.

This oxide capacity can be used in estimating the distribution ratio of oxygen between slag and molten metal and in monitoring the steelmaking operation. The activity of $\mathrm{Fe}_{\mathrm{t}} \mathrm{O}$ was also estimated in FetO-CaO- $\mathrm{SiO} 2$ slags in equilibrium with liquid iron at $1600^{\circ} \mathrm{C}$ by using the regular solution model.

In addition, the experimental determination of the activities of iron oxide in the ternary systems $\mathrm{A} 12 \mathrm{O} 3-{ }^{-} \mathrm{FeO}$ '-SiO2, $\mathrm{CaO}-{ }^{-} \mathrm{FeO}$ '-SiO2 and 'FeO'-MgO-SiO2 was carried out by other investigators ${ }^{[10]}$. Furthermore, important data on thermodynamic activity for slag systems are also available in the literature ${ }^{[11]}$.

\section{Experimental Procedure}

EFS has an EAF of 185 tons tapping capacity equipped with 133 MVA transformers, EAF has three jet modules and one burner mounted on upper shell for oxygen, natural gas and carbon injection three bottom porous plug for argon and nitrogen purging.

EAF molten steel samples are taken from each heat, according to E $1806-2001{ }^{\text {[6] }}$ (Standard Practice for Sampling Steel and Iron for Determination of Chemical Composition), identified by the heat number to determine chemical composition for elements $\mathrm{C}, \mathrm{Si}, \mathrm{Mn}, \mathrm{P}, \mathrm{S}, \mathrm{Cu}, \mathrm{Cr}, \mathrm{Ni}, \mathrm{Sn}, \ldots$,etc.

Table 1 shows EAF ranges of metal and slag samples analysis. 
Table (1): Ranges of metal and slag analysis.

\begin{tabular}{|c|c|c|c|c|}
\hline \multicolumn{5}{|c|}{ Metal } \\
\hline $\mathbf{C}$ & $\mathbf{S i}$ & $\mathbf{M n}$ & $\mathbf{P}$ & $\mathbf{S}$ \\
\hline $0.049-0.116$ & $0.001-0.0098$ & $0.007-0.071$ & $0.004-0.021$ & $0.018-0.062$ \\
\hline \multicolumn{5}{|c|}{ Slag } \\
\hline $\mathbf{C a O}$ & $\mathbf{S i O}_{\mathbf{2}}$ & $\mathbf{M g O}$ & $\mathbf{M n O}$ & $\mathbf{F e}_{\mathbf{t}} \mathbf{O}$ \\
\hline $23.97-49.23$ & $12.75-20.86$ & $5.6-10.4$ & $1.92-5.16$ & $19.92-30.321$ \\
\hline $\mathbf{A l}_{\mathbf{2}} \mathbf{O}_{\mathbf{3}}$ & $\mathbf{P}_{\mathbf{2}} \mathbf{O}_{\mathbf{5}}$ & & \\
\hline $2.5-6.11$ & $0.259-0.561$ & &
\end{tabular}

\subsection{EAF Process Description}

EAF process starts with scrap bucket charging inside the furnace followed by roof close and start arcing using three graphite electrodes for supplying electrical energy to the charge from transformer. At the start of melting process, the module system starts by burring mode while the oxygen and carbon jets purge oxygen and natural gas with certain ratio to provide chemical energy to the charge for melting proceeding.

After charge meltdown, DRI and lime continuous feeding starts and the module system starts foaming mode by purging oxygen and fine carbon particles for create foaming slag. The temperature of the melt was raised to about $1650^{\circ} \mathrm{C}$ before tapping.

After achieve required steel analysis furnace starts to tap the molten steel through eccentric bottom tapping (EBT) into a ladle of 185 tones capacity. During tapping, slag forming material, alloying elements and de-oxidant can be added.

After tapping, the ladle is transferred to ladle furnace-refining unit (LRF) to conduct the steel refining process. Metal and slag samples were taken from the furnace at different time intervals and from the ladle after final de-oxidation and composition adjustment. The temperature was measured just before sampling.

\section{RESULTS AND DISCUSSION}

The slag analysis was used to estimate the activity coefficient and activity of total ferrous oxide. The latter was utilized to assess the oxygen concentration in the metal.

\subsection{Activity Coefficient of Total Ferrous Oxide}

The model of regular ionic solutions was used in the present work to calculate the activity coefficient of total ferrous oxide in the slag. The atom or mol fraction of the component $i$ in solution is given by the ratio

$$
\mathbf{N i}=\frac{\mathbf{n i}}{\sum \mathbf{n}}
$$

where $n_{i}$ is the number of g-atoms or moles of component $i$ per unit mass of solution, and $\mathrm{n}$ the total number of $\mathrm{g}$-atoms or moles. 
According to this model, the activity coefficient of component $l, \gamma_{l}$ in a slag consisting of $\mathrm{k}$ components is given by:

$$
\ln l \gamma=\left[\frac{1}{R T} \sum_{i=1}^{l-i} x_{i} Q_{i l}+\sum_{i=L+1}^{k} x_{i} Q_{i l}-\sum_{i=1}^{K-1} \sum_{j=i+1}^{K} x_{i} x_{j} Q_{i j}\right]
$$

Where $\mathrm{X}_{\mathrm{i}}$ is the ionic fraction of the cation of component $i$ and $\mathrm{Q}_{\mathrm{ij}}$ is the energy of mixing of components $i$ and $j$ in $\mathrm{kJ}$.

The ionic fraction of the cation can be calculated from:

$$
X_{i}=\frac{v i n i}{\sum v i n i}
$$

where $v i$ is the number of cations in a molecule of component, $i$ and $n i$ is the number of moles of the cation in $100 \mathrm{~g}$ of the slag. The magnitudes of the energies of mixing ${ }^{[7]}$ are given in table 2; other magnitudes are assumed to be equal to zero. The following expression (Kozheurov equation) ${ }^{[8]}$ was obtained for the estimation of the activity coefficient of total ferrous oxide in the slag.

$$
\ln \gamma_{\mathrm{FetO}}=\frac{120.3}{T}\left[\begin{array}{c}
10 x_{\mathrm{CaO}}\left(x_{\mathrm{FetO}}+20.10 x_{\mathrm{FetO}}-1\right) \\
+25.10 x_{\mathrm{Al2O3}}\left(x_{\mathrm{FetO}}-4,73_{\mathrm{MnO}}+4.73_{\mathrm{MnO}}+4.16 x_{\mathrm{CaO}}\right. \\
\left.-5.94 x_{\mathrm{MgO}}-5.0 x_{\mathrm{SiO} 2}-1\right) \\
\left.+9.20 x_{\mathrm{SiO} 2}\left(4.54 x_{\mathrm{MnO}}-x_{\mathrm{FetO}}+12.27 x_{\mathrm{CaO}}+12.27 x_{\mathrm{MgO}}+1\right)\right]
\end{array}\right]
$$

\begin{tabular}{|c|c|c|c|}
\hline $\bar{~}(\mathrm{FeO})-(\mathrm{CaO})$ & $(\mathrm{FeO})-\left(\mathrm{SiO}_{2}\right)$ & $\overline{(\mathrm{FeO})-\left(\mathrm{Al}_{2} \mathrm{O}_{3}\right)}$ & $(\mathrm{MnO})-\left(\mathrm{SiO}_{2}\right)$ \\
\hline-10.0 & 9.2 & -25.1 & -41.8 \\
\hline$(\mathrm{MnO})-\left(\mathrm{Al}_{2} \mathrm{O}_{3}\right)$ & $(\mathrm{CaO})-(\mathrm{SiO} 2)$ & $\left.(\mathrm{CaO})-(\mathrm{Al2O})_{3}\right)$ & $(\mathrm{MgO})-\left(\mathrm{SiO}_{2}\right)$ \\
\hline 118.7 & 112.9 & -104.5 & -112.9 \\
\hline$(\mathrm{MgO})-\left(\mathrm{Al}_{2} \mathrm{O}_{3}\right)$ & $(\mathrm{SiO} 2)-\left(\mathrm{Al}_{2} \mathrm{O}_{3}\right)$ & $(\mathrm{CaO})-\left(\mathrm{P}_{2} \mathrm{O}_{5}\right)$ & \\
\hline 137.9 & 125.4 & -200.8 & \\
\hline
\end{tabular}

Table (2): Magnitudes of energy of mixing Qij of binary system $i j \mathrm{~kJ}$.

The total ferrous oxide in the slag, $\left(\mathrm{Fe}_{\mathrm{t}} \mathrm{O}\right)$, mass \%, is given by:

$$
\left(\mathrm{Fe}_{\mathrm{t}} \mathrm{O}\right)=(\mathrm{FeO})+0.9\left(\mathrm{Fe}_{2} \mathrm{O}_{3}\right)
$$

Where $\mathrm{FeO}$ and $\mathrm{Fe}_{2} \mathrm{O}_{3}$ are the stoichiometric iron oxides and 0.9 is the conversion factor of $\mathrm{Fe}_{2} \mathrm{O}_{3}$ to $\mathrm{FeO}$. The total ferrous oxide is considered as stoichiometric $\mathrm{FeO}$.

The activity coefficient of $\mathrm{Fe}_{\mathrm{t}} \mathrm{O}$ in $\mathrm{CaO}-\mathrm{SiO}_{2}-\mathrm{Al}_{2} \mathrm{O}_{3}-\mathrm{MgO}$ slags at $1600^{\circ} \mathrm{C}$ was determined by other researchers. ${ }^{[8]}$

\subsection{Activity of Total Ferrous Oxide in Slag}

The activity of total ferrous oxide was calculated by multiplying the activity coefficient obtained from equation 4 , by the cation fraction:

$$
a_{\left(\mathrm{Fe}_{t} \mathrm{O}\right)}=\gamma_{\left(\mathrm{Fe}_{t} \mathrm{O}\right)} X_{\mathrm{FeO}}
$$


The activity was used to assess the oxygen content.

\subsection{Effect of Concentration on Activity of Total Ferrous Oxide}

The relationship between activity and concentration of $\mathrm{Fe}_{\mathrm{t}} \mathrm{O}$ in the slag was investigated by using 268 samples collected from the furnace in the course of the steel making process. The high correlation coefficient indicates strong linear correlation between activity and concentration of $\mathrm{Fe}_{\mathrm{t}} \mathrm{O}$ over the whole investigated ranges of basicity and temperature. The range of basicity was from 1.879 to 2.36 and the temperature range was from 1590 to $1670^{\circ} \mathrm{C}$. Equation 7 also shows that the ratio of activity to concentration of $\mathrm{Fe}_{\mathrm{t}} \mathrm{O}$ in the range of parameters investigated is constant and equal to 0.0179 , the result may be expressed by:

$$
a_{\left(F e_{t} O\right)}=0.0179\left(F e_{t} O\right) \quad(r=0.9518)
$$

Figure 1, shows variation of the activity with the concentration of total ferrous oxide in the slag.

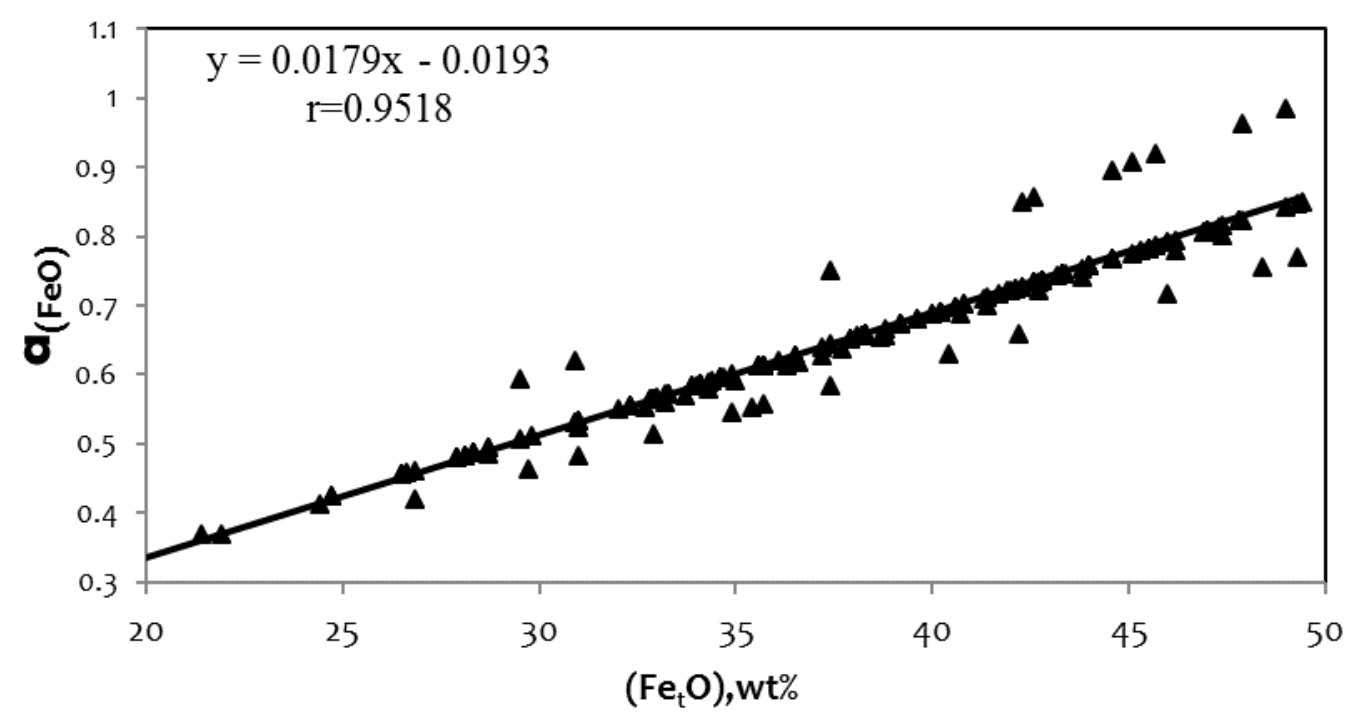

Fig. 1: Variation of the activity with the concentration of total ferrous oxide in the slag.

\subsection{Effect of Direct Reduced Iron on Concentration and Activity of Total Ferrous Oxide}

The ratios of DRI in the metallic charge (DRI \%) were 40, 50, 60, 70 and $80 \%$. The degree of metallization and carbon content of DRI were kept almost constant. Slag and metal samples were collected from the furnace just before metal tapping.

The respective results are shown in figures 2 and 3, and can be described by the empirical relationships:

$$
\mathrm{a}_{(\mathrm{FetO})}(\mathrm{DRI} \%)=0.0018(\mathrm{DRI} \%)+0.075 \quad(\mathrm{r}=0.951)
$$




$$
\left(\mathrm{Fe}_{\mathrm{t}} \mathrm{O}\right)(\mathrm{DRI} \%)=0.098(\mathrm{DRI} \%)+24.52 \quad(\mathrm{r}=0.952)
$$

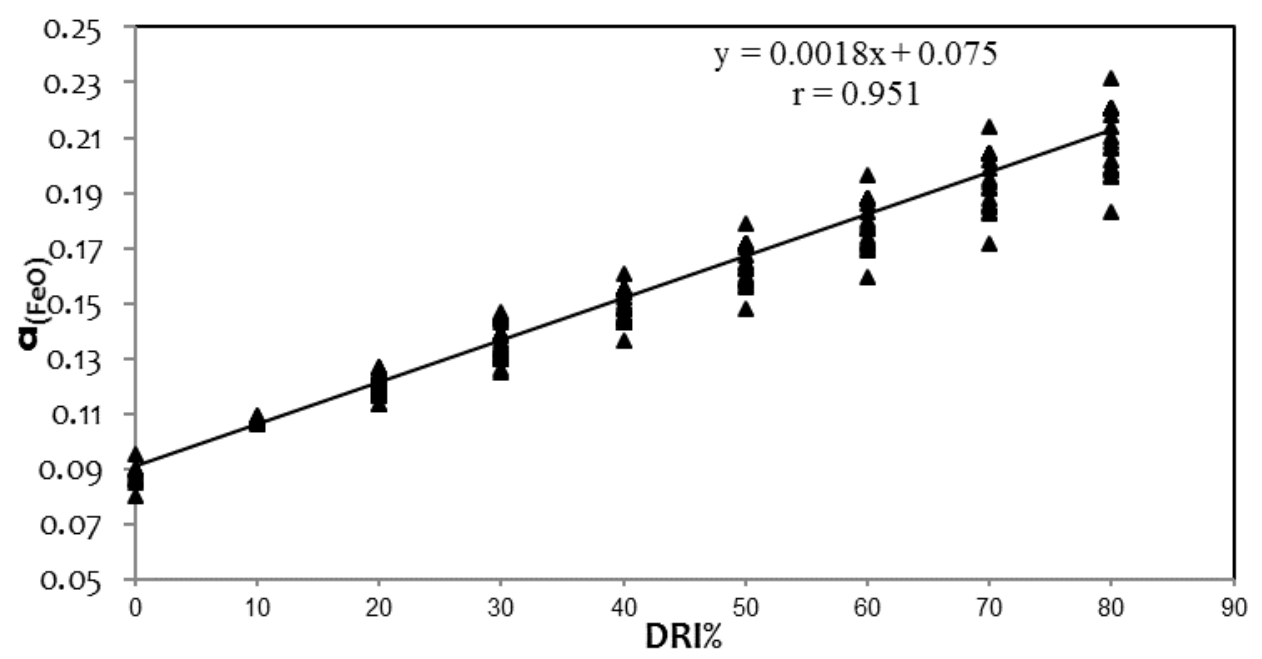

Fig. 2: Variation of DRI with the activity of total ferrous oxide in the slag.

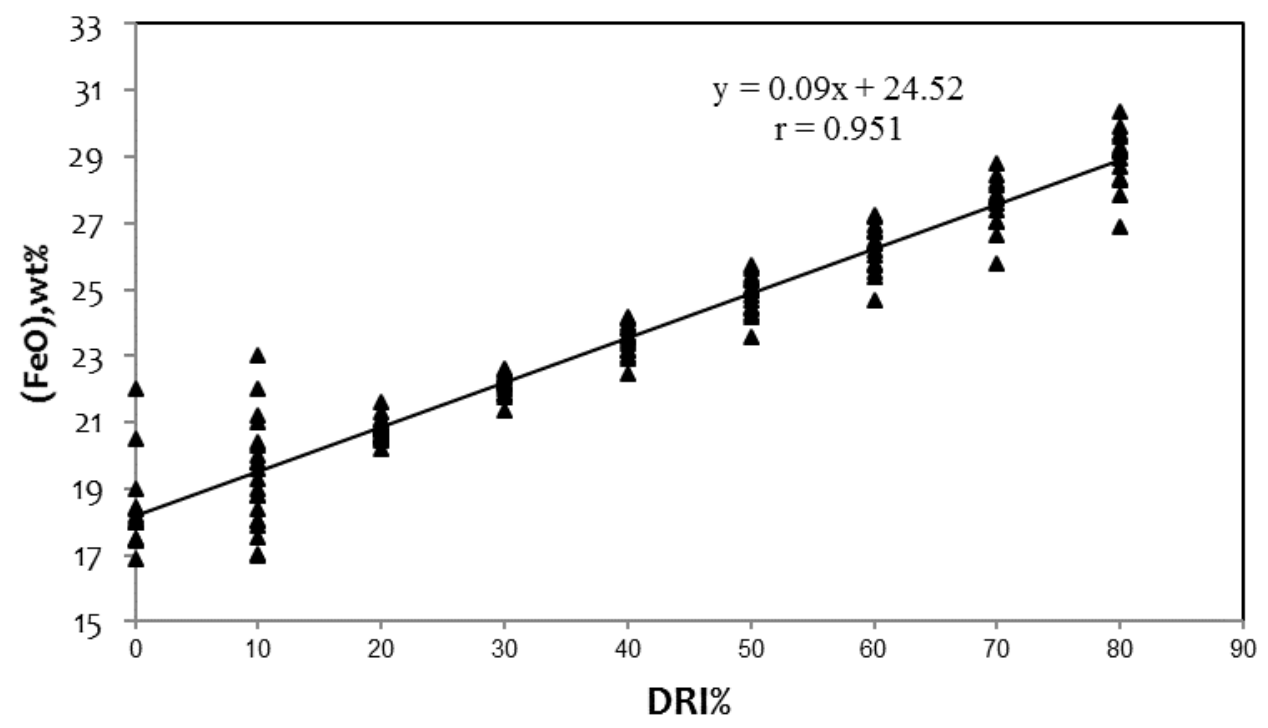

Fig. 3: Variation of DRI with the concentration of total ferrous oxide in the slag.

Equations 8 and 9 shows that the concentration and activity of total ferrous oxide in the slag increases with increasing DRI\% in the metallic charge, which may be attributed to the residual FeO in the DRI. Therefore, increasing the carbon content of DRI, addition of coke, pig iron or iron carbide seem to be necessary to decrease iron losses in the slag. The reduction of $\mathrm{FeO}$ by carbon also leads to $\mathrm{CO}$ formation ${ }^{[9]}$, which enhances refining by intensifying the bath boiling. ${ }^{[10]}$

\subsection{Solubility of Oxygen in Steel}

The relationship between the oxygen solubility in liquid steel and the activity of total ferrous oxide in the slag is given by: 


$$
a_{\left(\mathrm{Fe}_{t} \mathrm{O}\right)}=\frac{[\mathrm{O}]}{[\mathrm{O}]_{\operatorname{Max}}}
$$

Where $[\mathrm{O}]$ and $[\mathrm{O}]$ max are the concentrations of oxygen in the steel in equilibrium with the slag under consideration and its maximum solubility in steel in equilibrium with pure $\mathrm{FeO}$ slag, respectively. The maximum concentration of oxygen was estimated from $^{[11]}$ :

$$
[O]_{\max }=\exp \left[6.2953-\frac{14552}{T}\right]
$$

From equations 10 and 11, the oxygen concentration in steel can be assessed:

$$
[0]=a_{\left(\mathrm{Fe}_{\mathrm{t}} \mathrm{O}\right)} \exp \left[6.2953-\frac{14552}{\mathrm{~T}}\right]
$$

Calculated oxygen content, [O]calc, was correlated with the measured oxygen concentration, [O]obs, figure 4.

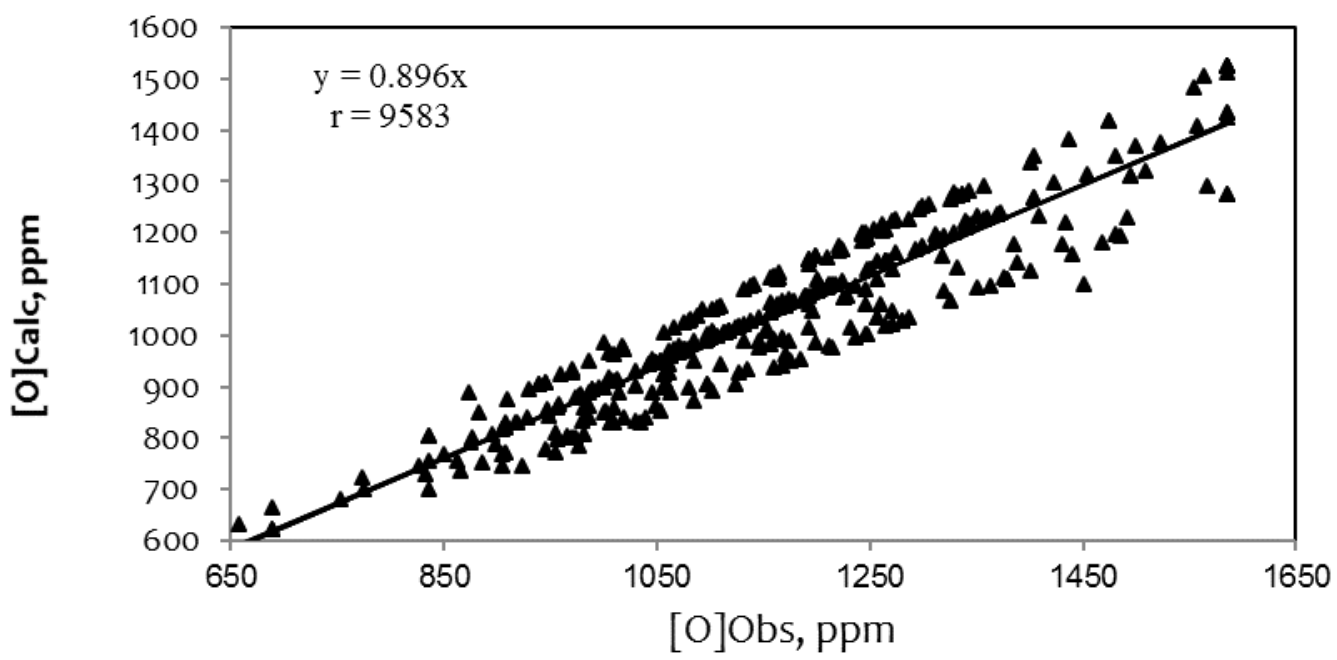

Fig. 4: Relationship between calculated and observed Oxygen concentration in the steel.

The following empirical formula was obtained:

$$
[O]_{\text {calc }}=0.896[O]_{\text {obs }} \quad(r=0.9583)
$$

The values of the correlation coefficient and the coefficient of [O]obs are close to unity, indicating satisfactory correlation between calculated and measured oxygen concentration. 


\subsection{The Activity of Oxygen in Steel}

$a_{[O]}$ is related to the concentration of oxygen as follows:

$$
a_{[O]}=\mathrm{f}_{\mathrm{O}}[O]
$$

The activity coefficient, $\mathrm{f}_{[\mathrm{O}]}$, depends on the metal composition as follows ${ }^{[12]}$ :

$$
\log f_{[O]}=-0.20[O]-0.45[C]-0.133[S]-0.021[M n]+0.07[P]-0.13[S i]
$$

The interaction parameters were taken from published work ${ }^{[13]}$ and the activity was obtained according to dilute solution model. Figure 5 represents the variation of the activity calculated with the concentration of oxygen .

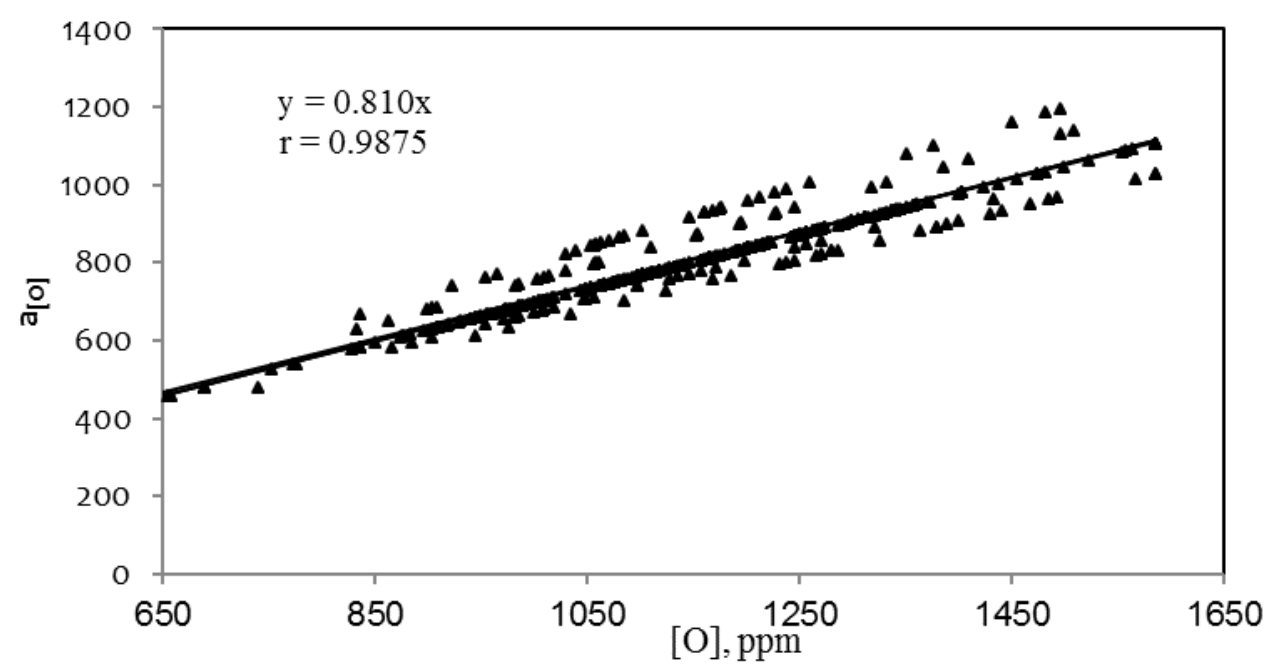

Fig. 5: Variation of the activity with the concentration of oxygen in the steel.

The straight line satisfies the formula:

$$
a_{[O]}=0.810[O] \quad(r=0.9875)
$$

Where temperature ranges from 1590 to $1690^{\circ} \mathrm{C}$.The high correlation coefficient indicates strong correlation between activity and concentration of oxygen in steel. The activity coefficient of oxygen as found:

$$
\mathrm{f}_{[O]}=0 \cdot 810
$$

\subsection{Calculation of Activity Coefficient and Activity of Carbon and Effect of} Carbon in Steel in Oxygen Activity Coefficient

In the present investigation 286 samples collected from the furnace in the temperature range between 1590 and $1670^{\circ} \mathrm{C}$ with carbon content ranging from 0.035 to $0.116 \%$ were used to correlate the activity coefficient of oxygen and activity of carbon with the carbon content of the metal, figures 6 and 7 . 


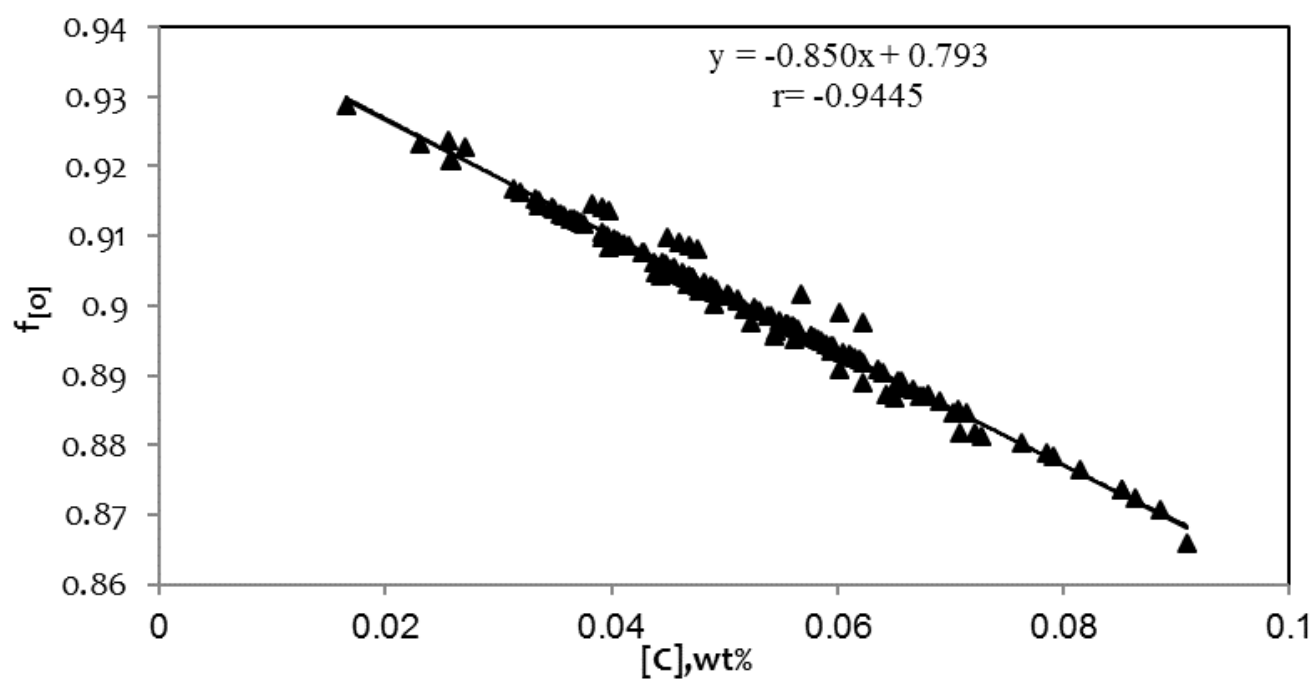

Fig. 6: Variation of the activity coefficient of oxygen with the concentration of carbon in steel.

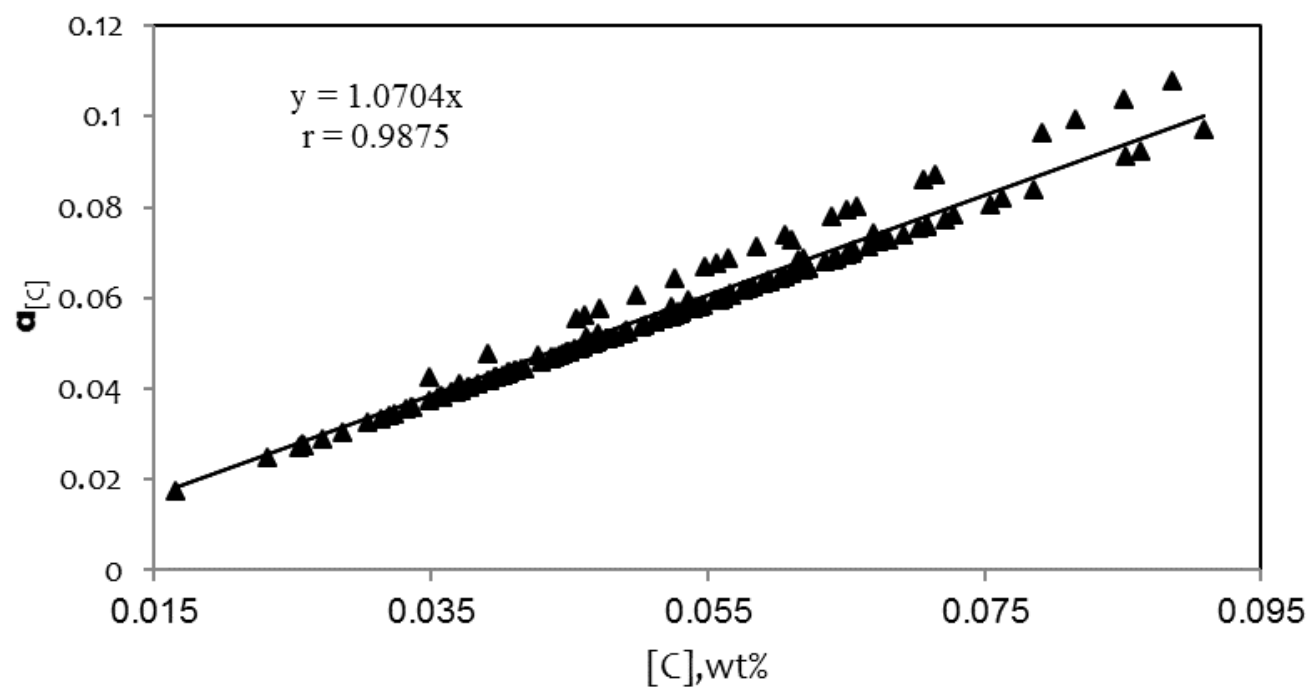

Fig. 7: Relationship between the activity and concentration of carbon in liquid steel in the temperature range $1590-1690^{\circ} \mathrm{C}$.

$$
\begin{array}{cc}
a_{[\mathrm{C}]}=1.0704[\mathrm{C}] & \mathrm{r}=0.9875 . \\
f_{[o]}=-0.850[C]+0.793 & r=-0.9455
\end{array}
$$

This equation 19 shows that an increase in the activity coefficient of carbon leads to a decrease in the activity coefficient of oxygen.

The activity coefficient of carbon was calculated by using:

$$
\log f_{[C]}=0.14[C]-0.012[\mathrm{Mn}]-0.34[O]+0.051[P]+0.08[S i]+0.046[S]
$$


The interaction parameters were taken from published work ${ }^{[13]}$ and the activity was obtained according to dilute solution model:

$$
a_{[C]}=f_{[C]}[C]
$$

The variation of $a_{[C]}$ with [C] is illustrated in figure 7, the temperature ranges between 1590 and $1670^{\circ} \mathrm{C}$, equation 18 shows that carbon activity coefficient:

$$
f_{[C]}=1.0704
$$

Based on the above-mentioned results, it can be noted that increased iron oxide activity in slag, oxygen activity in steel and metal losses in slag caused by higher ratios of DRI in metallic charge could be reduced by increasing carbon in DRI, adding carbon, iron carbide or pig iron as carbon source to the charge.

\subsection{Oxide Capacity of Slag}

The oxide capacity of the slag, $C_{O}$, may be obtained by using the oxidation reaction of molten iron as follows:

$$
\begin{gathered}
{[\mathrm{Fe}]+1 / 2 \mathrm{O}_{2}=(\mathrm{FeO})} \\
C_{O=\frac{(O)}{P}} \cdots \cdots \cdots \cdots \\
O 2^{\frac{1}{2}}
\end{gathered}
$$

Where $(\mathrm{O})$ is the oxygen equivalence of total ferrous oxide in slag. $\mathrm{Fe}_{\mathrm{t}} \mathrm{O}$ was calculated and multiplied by 0.227 , assuming that $\mathrm{Fe}_{\mathrm{t}} \mathrm{O}$ is stoichiometric $\mathrm{FeO}$, and $\mathrm{P}_{\mathrm{O} 2}$ is the partial pressure of oxygen in the gaseous phase, which can be found from:

$$
1 / 2 \mathrm{O}_{2}=[\mathrm{O}]
$$

with the equilibrium constant ${ }^{[14]}$

$$
\begin{array}{r}
K_{O}=\frac{a_{[O]}}{P_{O 2^{\frac{1}{2}}}} \ldots \ldots \ldots \ldots . . . . . \\
K_{O}=\exp \left[\frac{14201}{T}+0.27\right]
\end{array}
$$

The oxide capacity bases on the use of $\mathrm{Fe}_{t} \mathrm{O}$ as the main oxide component for oxygen transfer between slag and metal.

$$
C_{O}=\frac{(O)}{a_{[O]}} \exp \left[\frac{14201}{T}+0.27\right]
$$

\subsection{Effect of Temperature on Oxide Capacity}

The oxide capacity was calculated for 268 slag and the corresponding metal samples collected from the furnace in the temperature range between 1590 and $1670^{\circ} \mathrm{C}$, The results are illustrated in figure 8 . The straight line satisfies the formula: 


$$
\ln C_{O}(T)=\frac{25610}{T}-1.928 \quad r=(0.9765)
$$

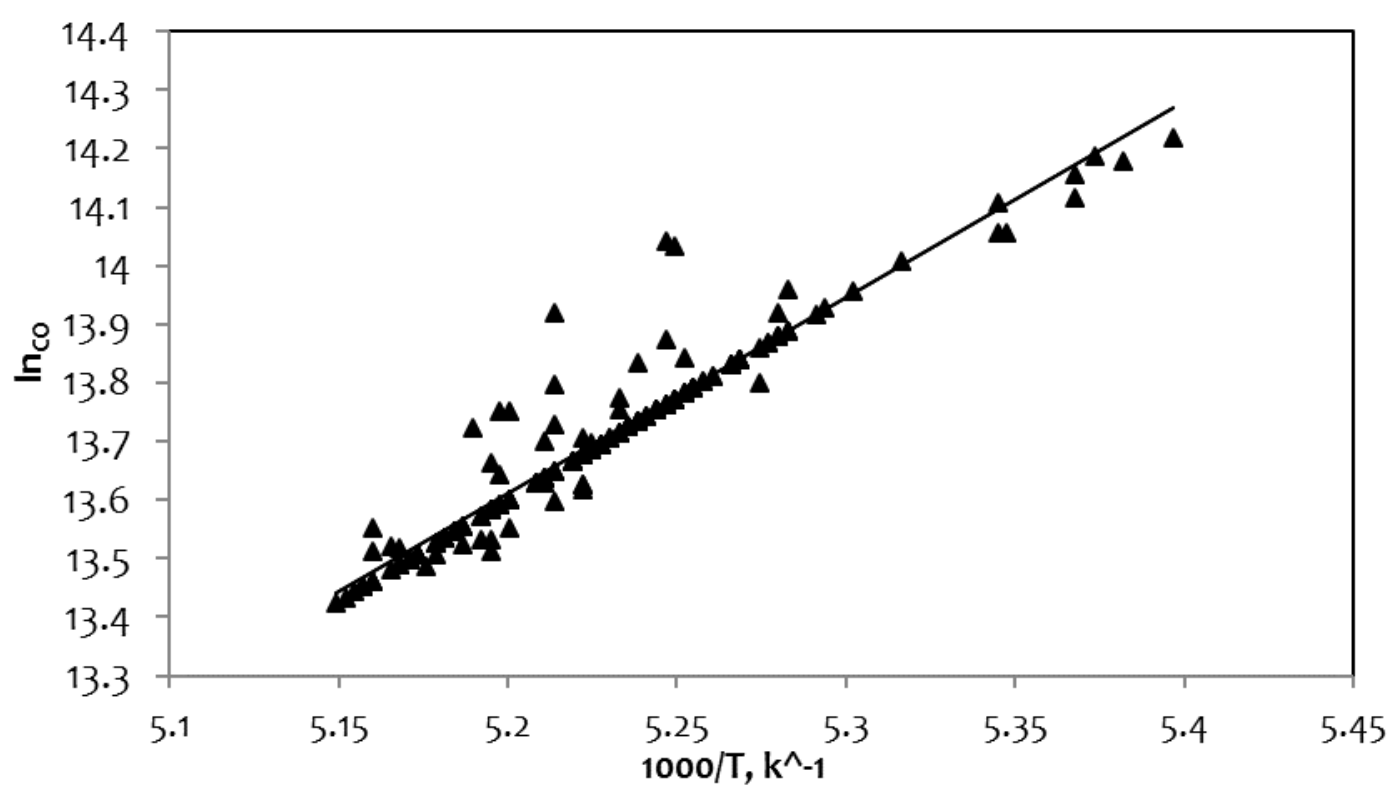

Fig. 8: Effect of temperature on oxide capacity of the slag.

The high correlation coefficient indicates a strong relationship between the logarithm of the oxide capacity and the reciprocal of the absolute temperature.

\subsection{Effect of Carbon on Oxide Capacity}

In order to reduce the temperature effect a narrow temperature range between $1630^{\circ} \mathrm{C}$ to $1650^{\circ} \mathrm{C}$ was taken figure 9 and equation 30 .

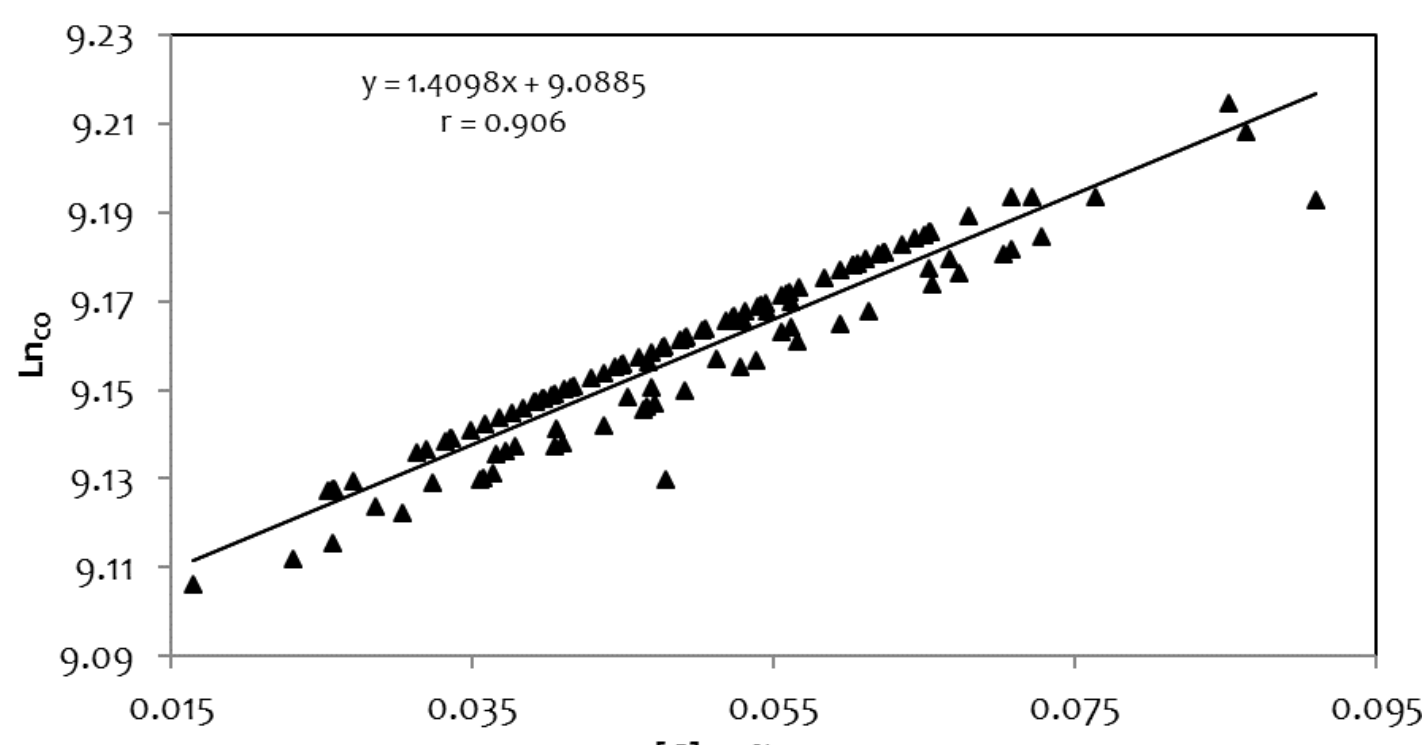

$[\mathrm{C}], \mathrm{wt} \%$

Fig. 9: Effect of carbon on oxide capacity of the slag. 


$$
\ln C_{O}=1.4098[\mathrm{C}]+9.0885 \quad(\mathrm{r}=0.906)
$$

Equation (30) shows that the oxide capacity increases with increasing carbon content of the metal.

\subsection{Effect of DRI Ratio on Oxide Capacity}

The oxide capacity of slag is affected by DRI ratio as illustrated in figure 10 , and correlated in equation 31 :

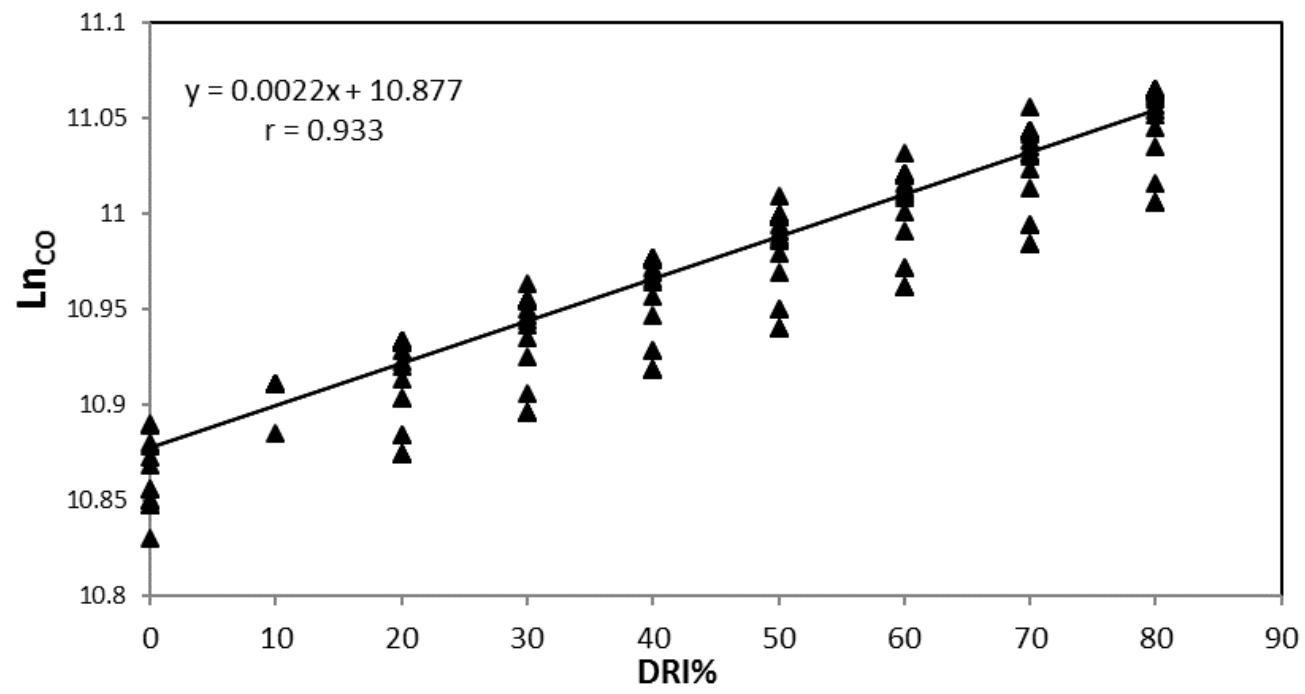

Fig. 10: Effect DRI ratio on oxide capacity of the slag.

$$
\ln C_{O}(\mathrm{DRI} \%)=2.2 * 10^{-3}(\mathrm{DRI} \%)+10.877 \quad(r=0.933)
$$

The results show an increase of slag oxide capacity with increasing DRI in metallic charge and reflecting strong correlation between DRI and slag oxide capacity.

\section{Conclusions}

- The activity coefficient of $\mathrm{Fe}_{t} \mathrm{O}$ can be calculated by using the model of regular ionic solution and the activity is satisfactory used to estimate the oxygen concentration in molten steel.

- Empirical relationships are given which show that both concentration and activity of $\mathrm{Fe}_{t} \mathrm{O}$ increases with increasing DRI in metallic charge.

- The ratio of activity to concentration of $\mathrm{Fe}_{t} \mathrm{O}$ is constant and equal to 0.0179.

- The activity coefficients of oxygen and carbon in steel are 0.810 and 1.0704, respectively.

- An "oxide capacity of slag" is mainly affected with temperature.

- The capacity increases with increasing carbon concentration in the bath.

- The "oxide capacity" increases with increasing DRI proportion in the charge.

\section{Acknowledgment}

The authors are so grateful to EZZ FLAT STEEL Company for supporting this study. 


\section{REFERENCES}

[1] Tsimbal, G. L.; Monarshvk, A. P.; Romanenko, A. S.; Voronkov, D. V. and Beletsk, V. A.: "Steel in the USSR". vol. 21, pp. 485-487, (1991).

[2] Gulyga, D. V. and Sushchenko, A. V.: "Steel in Translation". No. 12, pp. 33-34, (2003).

[3] Cárdenas, J. G. G.; Conejo, A. N. and Gnec, G. G.: "METAL 2007". pp. 3-6.

[4] Toulouevski, Y. N. and Zinurov, I. Y.: "Innovation in electric arc furnaces". pp. 1545, (2010).

[5] Derge, G. (Editor): "Basic open-hearth steelmaking with supplement on oxygen in steelmaking". $3^{\text {rd. }}$ edition, The American institute of metallurgical engineering, New York, p. 740, (1964).

[6] Coudrier, L.; Hopkins, D. W. and Wilkomirsky, I.: "Fundamentals of metallurgical processes". International series on materials science and technology, vol. $27,1^{\text {st. }}$ edition, Pergamon Press, Oxford, p. 196, (1978).

[7] Jung, S. M.; Rhee, C. H. and Min, D. J.: ISIJ Int., 42, No. 1, 63, (2002).

[8] Kozheurov, V. A.: "Thermodynamics of metallurgical slags". Metallurgizdat, Moscow, (1955), in: Filippov, S.: "The theory of metallurgical processes". Mir Publishers, Moscow, p. 227, (1975).

[9] Ban-Ya, S.: ISIJ Int., 33, No. 1, 2, (1993).

[10] Fredriksson, P. and Seetharman, S.: Steel Research Int., 75, No. 6, p. 375, (2004).

[11] Allibert, M. and Parrnd, R. edited by VDEh, Düsseldorf, p. 225, (1995).

[12] Meraikib, M.: ISIJ Int., 33, No. 11, 1174, (1993).

[13] Grigoryan. V. and Belyanchikov, L.: "Theoretical principals of electric steelmaking". Mir publisher, Moscow, p. 54, (1983),

[14] Grigoryan, V. and Belyanchikov, L.: "Theoretical principals of electric steelmaking". Mir publisher, Moscow, p. 108, (1983). 